\title{
PENGARUH PENAMBAHAN BENTONIT TERMODIFIKASI SEBAGAI PENGISI TERHADAP SIFAT MEKANIK DAN PENYERAPAN AIR KOMPOSIT EPOKSI
}

\section{THE EFFECT OF MODIFIED BENTONITE AS FILLER ON MECHANICAL PROPERTIES AND WATER ABSORPTION OF EPOXY COMPOSITE}

\author{
Alvian*, Kenrick, Iriany \\ Departemen Teknik Kimia, Fakultas Teknik, Universitas Sumatera Utara, \\ Jl. Almamater Kampus USU, Medan 20155, Indonesia \\ *Email : alvianong94@gmail.com
}

\begin{abstract}
Abstrak
Pada penelitian ini telah dilakukan pembuatan komposit epoksi berpengisi bentonit termodifikasi. Tujuan penelitian ini adalah untuk mendapatkan komposisi pengisi bentonit termodifikasi yang sesuai di dalam komposit epoksi dalam menghasilkan sifat mekanik seperti kekuatan tarik (tensile strength), kekuatan bentur (impact strength), serta penyerapan air (water absorption) yang terbaik. Dalam penelitian ini, resin epoksi dicampurkan dengan bentonit yang telah dimodifikasi dengan menggunakan surfaktan cetyltrimethylammonium bromide (CTAB) dengan variasi konsentrasi CTAB sebesar 0,05 M, $0,1 \mathrm{M}$, dan $0,15 \mathrm{M}$ serta ditambahkan $\mathrm{TiO}_{2}$. Pengisi bentonit termodifikasi dengan komposisi sebesar $5 \%, 10 \%, 15 \%$, dan $20 \%$ dari berat komposit dicampurkan dengan resin epoksi dan dicetak menggunakan metoda hand lay-up. Dari hasil karakterisasi FTIR diperoleh bahwa ikatan antara matriks dan pengisi yang dihasilkan hanya ikatan antar muka antara pengisi dengan matriks. Hasil pengujian sifat-sifat mekanik menunjukkan bahwa pada komposisi pengisi sebesar 5\% dengan konsentrasi surfaktan sebesar 0,1 M; diperoleh kekuatan tarik dan impak maksimum masing-masing sebesar 33,667 $\mathrm{MPa}$ dan 12564,9 J/m². Hasil uji mekanik selanjutnya didukung oleh analisis scanning electron microscopy (SEM). Pada uji daya serap air, kekuatan penyerapan air meningkat seiring bertambahnya komposisi pengisi.
\end{abstract}

Kata kunci : resin epoksi, bentonit, sifat mekanik, penyerapan air, hand lay-up

\begin{abstract}
Research about the application of modified bentonite as filler in epoxy has been done for the purpose of getting the best composition of modified bentonite as filler at epoxy composite to obtain the best mechanical properties such as tensile strength, impact strength and the water absorption. In this research, epoxy resin mixed with bentonite which have been modified using cetyltrimethylammonium bromide (CTAB) surfactant with various concentrations of 0,05M, 0,1M, and 0,15M. Modified bentonite filler and $\mathrm{TiO}_{2}$ then mixed with epoxy resin with various concentration of 5\%, 10\%, 15\%, and $20 \%$ of filler from the total mass of the composite and then the composite was produced with hand lay-up method. The result of FTIR characterization showed that the bond between matrix and the filler produced was only interfacial bonding. The result of the mechanical properties test indicated that $5 \%$ of filler composition with 0,1M of surfactant concentration obtained the maximum value of tensile strength and mechanical strength respectively 33,667 $\mathrm{MPa}$ and 12564,9 $\mathrm{J} / \mathrm{m}^{2}$. The result of mechanical properties test was supported by analysis of Scaning Electron Microscopy (SEM). On the test of water absorption, the water absorption capacity increased along with the increased of filler composition.
\end{abstract}

Keywords : epoxy resin, bentonite, mechanical properties, water absorption, hand lay-up.

\section{Pendahuluan}

Pada zaman sekarang ini, penelitian tentang bahan polimer sedang berkembang. Hal ini dikarenakan bahan polimer memiliki beberapa sifat yang lebih unggul jika dibandingkan dengan bahan logam ataupun bahan keramik seperti tahan korosi dan temperatur pemrosesan yang relatif lebih rendah. Pada umumnya, bahan polimer dicampurkan dengan bahan lain untuk memperoleh sifat yang lebih baik, yang dikenal sebagai bahan komposit.

Mineral sebagai pengisi digunakan untuk mengurangi biaya material dengan menggantikan sebahagian dari polimer dengan material yang tidak mahal. Saat ini banyak mineral termodifikasi yang digunakan untuk 
memodifikasi karakteristik pengolahan atau sebagian sifat produk komposit [9]. Salah satu contoh mineral yang digunakan adalah bentonit, hal ini dikarenakan harga dari bentonit yang cukup murah dan juga mudah didapat. Kandungan utama dari bentonit yaitu silikat. Jika suatu polimer dicampur dengan silikat, maka material ini akan menunjukkan peningkatan yang dramatis pada sifat-sifat seperti mekanik dan termal melebihi sifat polimer murninya. Selain itu, karena rentang skala pengisi yang dimiliki oleh komposit ini dapat menjadi sangat kecil yaitu berada pada skala nanometer (1-100 nm) yang dapat meminimalkan terjadinya penghamburan cahaya, maka material tersebut juga bersifat transparan [5].

Pemodifikasi organik yang dapat digunakan untuk keperluan pemrosesan ini adalah cairan ionik (Ionic Liquid). Cairan ionik adalah material yang hanya terdiri atas spesies ionik (kation dan anion), tidak mengandung molekul netral tertentu, dan mempunyai titik leleh relatif rendah, yaitu pada suhu $<100{ }^{\circ} \mathrm{C}$, walaupun umumnya pada suhu kamar. Salah satu pemodifikasi ionic liquid yang digunakan adalah cetyltrimethylammonium bromide (CTAB). Hal ini dikarenakan sifat dari CTAB yang mampu menurunkan kepolaran dari clay yang akan dijadikan sebagai pengisi pada komposit [5].

Selain mineral alam, titanium dioksida $\left(\mathrm{TiO}_{2}\right)$ dalam bentuk carbon nano tube juga dapat digunakan sebagai bahan pengisi untuk meningkatkan sifat dari komposit. Menurut Anandhan dan Bandyopadhyay [12] $\mathrm{TiO}_{2}$ dapat meningkatkan sifat mekanik dan termal pada suatu komposit secara signifikan.

Ataiwi dan Abdul-Hameed pada tahun 2010 melakukan percobaan dengan membuat komposit polyester tak jenuh dengan pengisi bentonit yang telah diaktivasi dengan $\mathrm{HCl}$ dan $\mathrm{Na}_{2} \mathrm{CO}_{3}$. Hasil yang didapatkan adalah peningkatan maksimum sifat kekerasan komposit pada penambahan 5\% berat bentonit [3]. Bukit dkk pada tahun 2013 melakukan modifikasi bentonit alam menjadi material nano partikel sebagai pengisi nano pada High Density Polyethylene (HDPE). Hasil yang didapatkan adalah peningkatan tensile strength pada penambahan 2 sampai $6 \%$ pengisi dan penurunan dengan penambahan di atas $6 \%$. Pada hasil analisis SEM komposit juga menunjukkan bahwa matriks dan pengisi telah menyatu [11]. Berdasarkan uraian di atas, maka bentonit termodifikasi akan digunakan sebagai salah satu pengisi pada matriks epoksi untuk mengkaji keefektifannya dalam meningkatkan sifat mekanik matriks. Selain itu, pemilihan bentonit ini juga atas pertimbangan cadangannya yang melimpah dan tersebar hampir di seluruh Indonesia.
Teori

Resin epoksi didefinisikan sebagai molekul yang terdiri atas lebih dari satu gugus epoksi. Gugus epoksi juga disebut sebagai oxirane atau gugus ethoxyline yang memiliki struktur seperti pada Gambar 1.<smiles>[R]C1CO1</smiles>

Gambar 1. Struktur gugus epoxide

Resin epoksi termasuk dalam jenis polimer termoset. Terdapat dua tipe utama dari resin epoksi, yaitu epoksi glycidyl dan epoksi nonglycidyl. Glycidyl merupakan epoksi yang dibuat melalui reaksi kondensasi campuran antara dihydroxy, dibasic acid atau diamine dengan epichlorohydrin. Epoksi glycidyl diklasifikasikan menjadi glycidyl-ether, glycidyl ester, dan glycidyl-amine. Sedangkan epoksi non-glycidyl dibuat dari peroksidasi ikatan ganda olefin. Epoksi non-glycidyl dapat berupa resin epoksi aliphatic atau cycloaliphatic [10].

Bentonit merupakan mineral clay yang dihasilkan dari hasil pelapukan dan reaksi hidrotermal batuan lava (vulkanik). Sebagian besar bentonit merupakan mineral smektit, biasanya montmorillonite. Selain montmorillonite, bentonit juga mengandung mineral pengotor lain, seperti kuarsa, illite, kristobalit, feldspar, kalsit, gipsum, kaolinit dan plagioklas. [4]. Selain bentonit, pada penelitian ini juga ditambahkan Titanium Dioksida yang bisa disebut Titania atau Titanium (IV) oksida yang merupakan bentuk oksida dari titanium secara kimia dapat dituliskan $\mathrm{TiO}_{2}$. Senyawa ini dimanfaatkan secara luas dalam bidang anatas sebagai pigmen, bakterisida, pasta gigi, fotokatalis dan elektroda dalam sel surya. Titanium dioksida $\left(\mathrm{TiO}_{2}\right)$ dapat dihasilkan dari reaksi antara senyawa titanium tetraklorida $\left(\mathrm{TiCl}_{4}\right)$ dan $\mathrm{O}_{2}$ yang dilewatkan melalui lorong silika pada suhu $700^{\circ} \mathrm{C}[16]$.

\section{Metodologi Penelitian}

Bahan-bahan yang digunakan dalam penelitian ini adalah resin epoksi dan epoxy harderner sebagai matriks, cetyltrimethylammonium bromida sebagai surfaktan, bentonit dan titanium dioksida $\left(\mathrm{TiO}_{2}\right)$ sebagai pengisi. Peralatan yang digunakan dalam penelitian ini adalah hot plate, magnetic stirrer, oven, dumble cutter, cetakan malam, lilin mainan, kaca, dan roller.

\section{Prosedur Penelitian Modifikasi Bentonit}


Bentonit ditambahkan ke larutan CTAB pada suhu $50^{\circ} \mathrm{C}$ dan diaduk secara terus menerus dengan perbandingan $200 \mathrm{ml}$ larutan CTAB dengan konsentrasi tertentu untuk setiap 10 gram bentonit. Produk dicuci dan difiltrasi dengan 500 $\mathrm{ml}$ larutan aquadest dengan perbandingan 50:50. Produk dimasukkan ke dalam oven dengan suhu $80^{\circ} \mathrm{C}$ selama 6 jam.

\section{Penyediaan Pengisi}

Lima gram bentonit yang telah dimodifikasi dimasukkan ke dalam erlenmeyer dan ditambahkan 4 gram $\mathrm{TiO}_{2}$ dan $15 \mathrm{ml}$ etanol kemudian diaduk selama 5 jam. Produk dikeluarkan dan disaring yang kemudian dimasukkan ke dalam oven dengan suhu $120^{\circ} \mathrm{C}$ selama 5 jam. Setelah itu, produk dikalsinasi pada suhu $400^{\circ} \mathrm{C}-500^{\circ} \mathrm{C}$ selama 5 jam.

\section{Penyediaan Komposit}

Resin epoksi dan epoxy hardener dicampurkan dengan rasio 1:1 dan diaduk dengan merata. Ditambahkan pengisi sesuai dengan variasi yang telah ditentukan kemudian diaduk secara perlahan hingga merata. Campuran dituang ke cetakan kaca yang telah disediakan yang telah diberikan bahan pelicin seperti gliserin atau kit mobil. Permukaan cetakan diratakan dan ditunggu hingga kering kemudian dilepas dari cetakan dan dihaluskan bagian permukaannya.

\section{Analisis Produk}

Analisis terhadap komposit yang dihasilkan meliputi uji kekuatan tarik, kekuatan bentur, penyerapan air, FTIR(Fourier Transform Infra Red), dan SEM (Scanning Electron Microscopy)

\section{Hasil dan Pembahasan \\ Analisis Kekuatan Tarik Komposit}

Gambar 2 menunjukkan pengaruh komposisi pengisi bentonit termodifikasi pada matriks epoksi terhadap kekuatan tarik komposit.

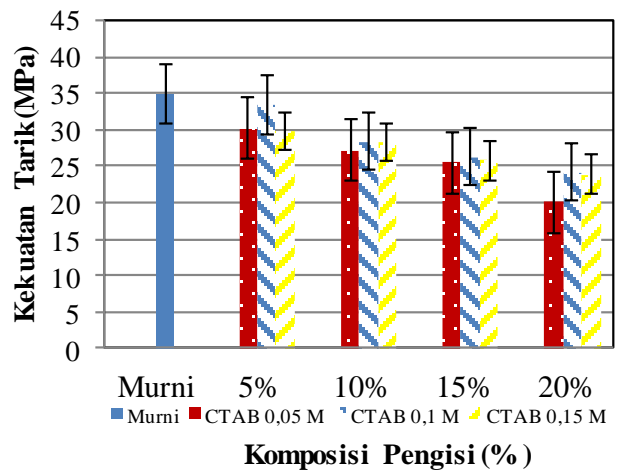

Gambar 2. Pengaruh Komposisi Pengisi Terhadap Kekuatan Tarik Komposit Epoksi Berpengisi Bentonit Termodifikasi
Penurunan kekuatan tarik pada sistem epoksi-bentonit dapat dijelaskan dengan dua alasan. Pertama, dengan lebih banyak kandungan bentonit di dalam epoksi, maka distribusi bentonit di dalam epoksi akan semakin tidak homogen, sehingga memungkinkan terjadinya penggumpalan bentonit atau yang biasa disebut dengan aglomerasi. Alasan kedua adalah, terjadi gelembung udara selama proses pencampuran akibat dari viskositas epoksi yang semakin tinggi. Peningkatan viskositas yang dialami oleh campuran epoksi dan bentonit disebabkan oleh meningkatnya secara drastis daerah interfasa dan interaksi interfasa antara bentonit yang telah termodifikasi dengan resin epoksi [7]. Hal ini juga didukung oleh hasil analisis SEM yang menunjukkan bahwa pada komposit terdapat aglomerasi dan void.

Dari hasil uji kekuatan tarik di atas juga dapat dilihat bahwa kekuatan tarik komposit meningkat seiring dengan naiknya konsentrasi CTAB pada kandungan pengisi yang sama. Namun, penambahan konsentrasi surfaktan CTAB lebih dari $0,1 \mathrm{M}$ akan mengakibatkan penurunan kekuatan tarik. Hal ini disebabkan oleh konstannya tegangan permukaan yang dapat diturunkan oleh surfaktan walaupun konsentrasi surfaktan ditingkatkan. Bila surfaktan ditambahkan melebihi konsentrasi ini maka surfaktan akan mengagresi terbentuknya misel. Konsentrasi dimana surfaktan akan membentuk suatu fasa terdispersi yang terdiri dari misel bersama dengan molekul surfaktan individu dalam campuran disebut dengan Critical Micelle Concentration (CMC) [2,19]. Fasa terdispersi inilah yang memungkinkan terjadinya penurunan sifat dari kekuatan tarik komposit pada konsentrasi CTAB $0,15 \mathrm{M}$ dimana semakin banyak fasa padatan yang terdapat pada pengisi sebagai akibat terdapatnya fasa terdispersi dari CTAB yang mengakibatkan semakin banyak terjadinya aglomerasi pada komposit. Hal ini juga didukung oleh hasil pemanjangan saat putus komposit di mana komposit dengan surfaktan $0,1 \mathrm{M}$ memiliki nilai yang lebih tinggi dari komposit dengan surfaktan $0,15 \mathrm{M}$.

\section{Analisis Pemanjangan Saat Putus (Elongation at Break) Komposit}

Gambar 3 menunjukkan pengaruh komposisi pengisi bentonit termodifikasi pada matriks epoksi terhadap pemanjangan saat putus komposit.

Penurunan nilai elongation at break disebabkan oleh adanya penumpukan atau aglomerasi pada pengisi yang menyebabkan komposit menjadi lebih brittle. Selain penumpukan atau aglomerasi, penurunan nilai elongation at break yang seiring dengan penambahan komposisi pengisi merupakan suatu hal yang umum dijumpai pada material polimer 
dengan pengisi non-organik, pengisi non-organik cenderung lebih kaku yang secara keseluruhan akan mengakibatkan penurunan strain pada matriks sehingga menurunkan nilai elongation at break pada komposit $[6,14]$.

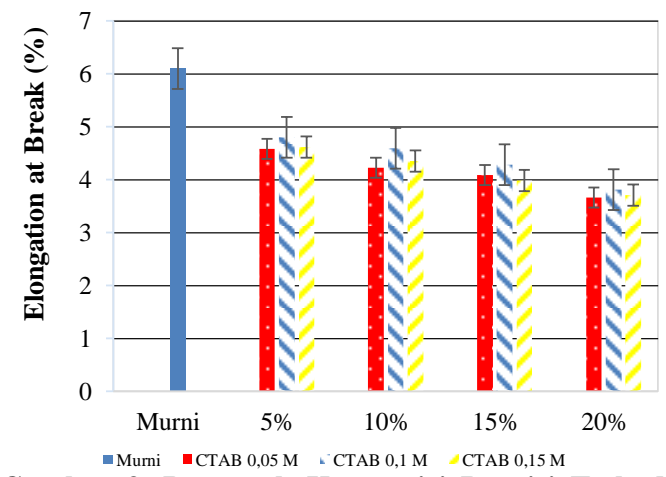

Gambar 3. Pengaruh Komposisi Pengisi Terhadap Pemanjangan Saat Putus Komposit Epoksi Berpengisi Bentonit Termodifikasi

\section{Analisis Kekuatan Bentur Komposit}

Gambar 4 menunjukkan pengaruh komposisi pengisi bentonit termodifikasi pada matriks epoksi terhadap kekuatan bentur komposit.

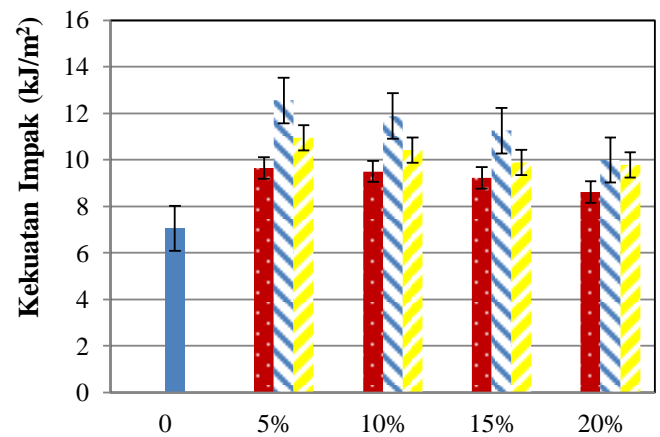

Gambar 4. Pengaruh Komposisi Pengisi Terhadap Kekuatan Bentur Komposit Epoksi Berpengisi Bentonit Termodifikasi

Peningkatan sifat pada komposit umumnya didapatkan pada komposisi pengisi yang rendah $(\leq 5 \%)$ [13]. Peningkatan kekuatan bentur dapat disebabkan karena adanya peran pengisi dalam meningkatkan ketahanan bentur dari komposit, dalam hal ini pengisi berperan sebagai pembentuk titik dimana mulainya pematahan (crack formation) dan media pemindahan tegangan (stress transferring medium) [15]. Namun penurunan dari kekuatan bentur pada komposit dengan komposisi pengisi yang lebih tinggi disebabkan oleh adanya aglomerasi, penumpukan, void, dsb [1].

Selain bentonit, juga ditambahkan $\mathrm{TiO}_{2}$. Fungsi dari $\mathrm{TiO}_{2}$ adalah untuk meningkatkan kekuatan bentur pada komposit [12]. Kishore dkk [1] melakukan penelitian kekuatan bentur dengan menggunakan bentonit yang telah dimodifikasi dengan surfaktan sebagai pengisi pada komposit. Hasil yang didapatkan adalah penurunan sifat kekuatan bentur dibawah dari sifat kekuatan bentur matriks dengan komposisi pengisi di atas 4\%. Dari hasil yang didapatkan pada penelitian ini dapat disimpulkan kekuatan bentur pada setiap komposisi pengisi tetap melebihi kekuatan bentur matriks epoksi murni meskipun terjadi penurunan pada penambahan komposisi pengisi yang lebih besar dari $5 \%$ yang disebabkan oleh aglomerasi dan void tetapi nilai kekuatan bentur tetap berada di atas nilai kekuatan bentur matriks epoksi murni sehingga dapat diambil kesimpulan bahwa $\mathrm{TiO}_{2}$ mampu meningkatkan sifat kekuatan bentur dari komposit yang dihasilkan.

\section{Karakteristik Scanning Electron Microscope (SEM) Patahan Komposit Epoksi}

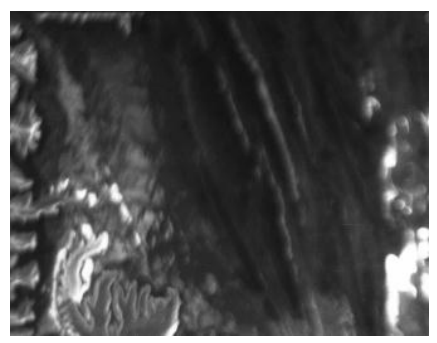

(a)

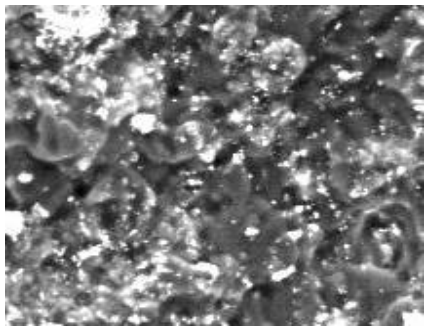

(b)

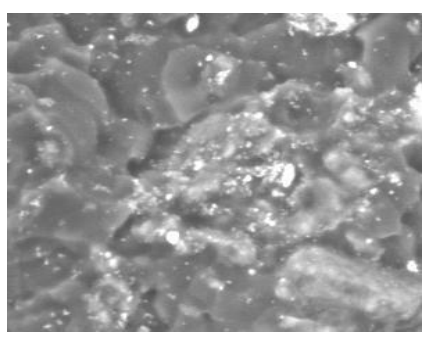

(c)

Gambar 5 Analisis SEM Patahan Komposit Epoksi Berpengisi Bentonit

(a) Tanpa Modifikasi Dengan Komposisi Pengisi 5\% dan Perbesaran 300x

(b) Termodifikasi Dengan Komposisi Pengisi 5\%, Konsentrasi CTAB 0,1 M, dan Perbesaran 500x

(c) Termodifikasi Dengan Komposisi Pengisi 5\%, Konsentrasi CTAB 0,1 M, dan Perbesaran 1000x 
Dari gambar 5 dapat dilihat karakteristik SEM dari patahan komposit epoksi berpengisi bentonit termodifikasi. Gambar tersebut menunjukkan hasil analisa SEM komposit epoksi berpengisi bentonit termodifikasi dan tanpa modifikasi. Pada Gambar 5 (a) dapat dilihat bahwa pada patahan komposit epoksi berpengisi bentonit tanpa modifikasi penyebaran pengisi sangat tidak merata atau hanya tertumpuk pada satu sisi saja sedangkan pada sisi lain sama sekali tidak terdapat pengisi. Hal ini membuktikan bahwa modifikasi dengan menggunakan surfaktan dapat meningkatkan dispersi bentonit pada matriks.

Gambar 5 (b) dan Gambar 5 (c) memperlihatkan bahwa distribusi pengisi pada patahan komposit epoksi berpengisi bentonit termodifikasi telah tersebar dengan merata pada matriks epoksi. Jika dibandingkan dengan hasil SEM patahan komposit epoksi berpengisi bentonit tanpa modifikasi, pengisi pada komposit epoksi berpengisi bentonit termodifikasi tersebar dengan merata sehingga dapat diambil kesimpulan bahwa modifikasi pada bentonit meningkatkan pendispersian antara pengisi dan matriks sehingga dapat meningkatkan sifat mekanik komposit.

\section{Analisis Penyerapan Air Komposit}

Gambar 6, 7, dan 8 menunjukkan pengaruh komposisi pengisi bentonit termodifikasi pada matriks epoksi terhadap penyerapan air komposit. Hasil yang didapatkan dari Gambar 6, 7 dan 8 menunjukkan bahwa kemampuan komposit dalam menyerap air meningkat seiring dengan bertambahnya komposisi pengisi dalam komposit.

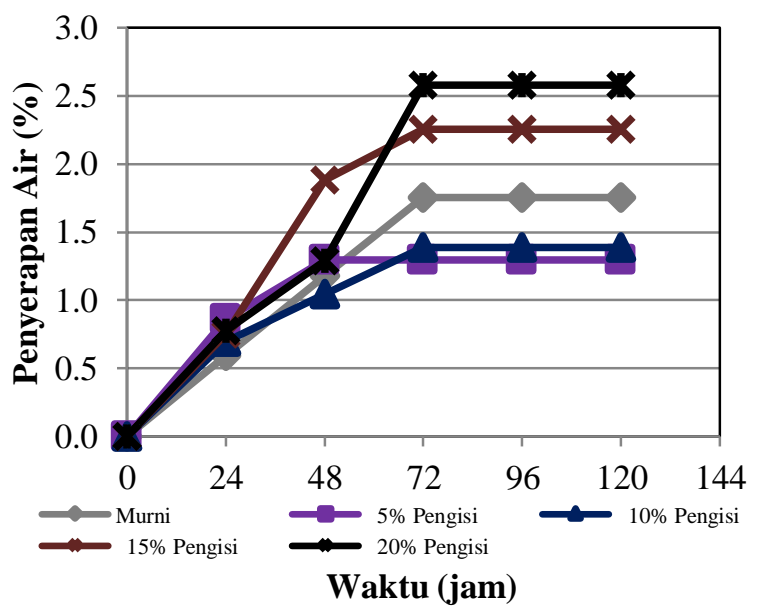

Gambar 6. Pengaruh Komposisi Pengisi Terhadap Penyerapan Air Komposit Epoksi Berpengisi Bentonit Termodifikasi Pada Konsentrasi Surfaktan 0,05 M.

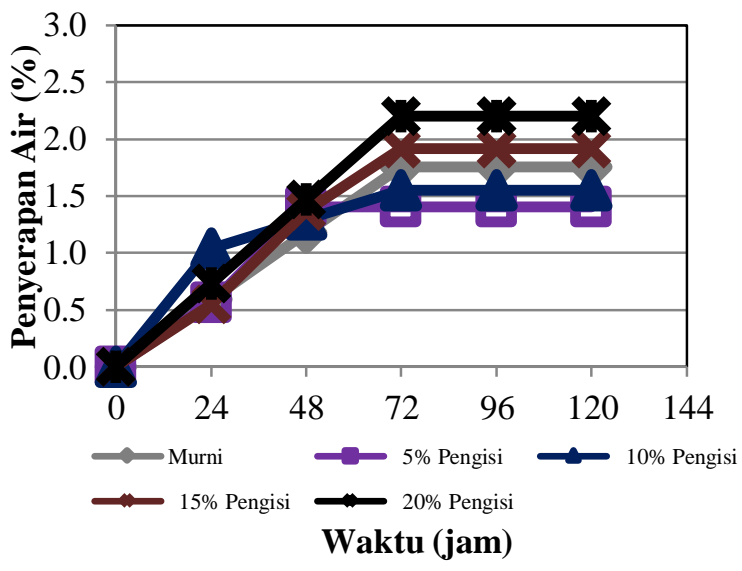

Gambar 7. Pengaruh Komposisi Pengisi Terhadap Penyerapan Air Komposit Epoksi Berpengisi Bentonit Termodifikasi Pada Konsentrasi Surfaktan 0,1 M.

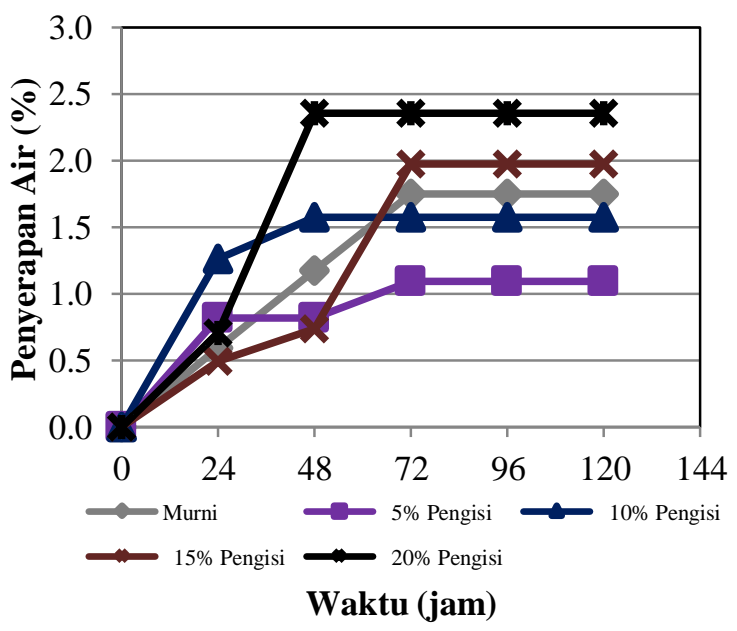

Gambar 8. Pengaruh Komposisi Pengisi Terhadap Penyerapan Air Komposit Epoksi Berpengisi Bentonit Termodifikasi Pada Konsentrasi Surfaktan 0,15 M.

Ada beberapa faktor yang dapat terjadi untuk menjelaskan besar kecilnya nilai dari penyerapan air pada komposit dengan pengisi bentonit termodifikasi. Faktor yang pertama adalah sifat hidrofilik dari bentonit dan sifatnya yang dapat menahan molekul air. Faktor ini mempengaruhi meningkatnya penyerapan air pada komposit dengan peningkatan kandungan bentonit [6]. Faktor yang kedua adalah void, void yang terbentuk pada proses penyediaan komposit dapat menyebabkan meningkatnya penyerapan air pada komposit karena void dapat menyebabkan terbentuknya jalur untuk air agar dapat terserap ke dalam komposit [8], hal ini yang menyebabkan penyerapan air pada komposit dengan komposisi pengisi yang lebih besar mengalami peningkatan sifat penyerapan air. Faktor yang ketiga adalah sifat hidrofobik yang didapatkan setelah dilakukan modifikasi kimia pada bentonit dapat 
menurunkan penyerapan air pada komposit berpengisi clay $[18,17]$. Sifat hidrofobik ini yang menyebabkan kemampuan penyerapan air komposit dengan komposisi pengisi dibawah $10 \%$ lebih rendah dari kemampuan penyerapan air resin epoksi murni.

\section{Kesimpulan}

Komposisi pengisi terbaik pada penelitian ini adalah pada 5\% jumlah pengisi karena peningkatan tertinggi sifat mekanik komposit didapat pada saat komposisi pengisi sebanyak 5\%, konsentrasi CTAB terbaik yang didapatkan pad penelitian ini adalah $0,1 \mathrm{M}$. Hasil untuk analisis penyerapan air komposit adalah penyerapan air suatu komposit akan bertambah seiring dengan meningkatnya jumlah pengisi dalam komposit.

\section{Daftar Pustaka}

[1] A. D. Kishore, B. Venkatesh, M. A. Kumar, A. Ramesh, K. N. Murthy, and N. Karthikeyan, Hydrophilic Modified Clay Nanocomposites : Effect of Clay on Thermal and Vibrational Properties, International Letters of Chemistry, Physics and Astronomy, 27, (2014) 73-86.

[2] A. Zhang and D. Zhang, Effects of Void on Physical Properties of Hygrothermal Conditioned CFRP, 652-654, (2013) 3-6.

[3] A. H. Ataiwi and A. A. Abdul-Hamead, Preparing Polyester-Bentonit Clay Nano Composite and Study Some of Its Mechanical Properties, Emirates Journal for Engineering Research. 17, (2012) 57-61.

[4] E. Juliani, Aktivasi Bentonit Alam Sebagai Bahan Pengisi Pada Komposit Polietilen/High Density Polyethyline (HDPE) Untuk Bahan Teknik, Tesis, Universitas Sumatera Utara, Medan, (2013).

[5] I. I. Rosyadi, A. Mudzakir, and B. Anwar, Preparasi dan Karakterisasi Bentonit Termodifikasi Surfaktan Kationik Fatty Imidazolinium, Jurnal Sains dan Teknologi Kimia, 1, (2010) 112-120.

[6] J. Basim-Abu, K. Al-Malah and R. Sawalha, Study on Bentonite- Unsaturated Polyester Composite Materials, Journal of Reinforced Plastics and Composites, 21, (2002).

[7] K. Wang, L. Chen, J. Wu, M. L. Toh, C. He, and A. F. Yee, Epoxy Nanocomposites with Highly Exfoliated Clay : Mechanical Properties and Fracture Mechanisms, Macromolecules, 38, (2005) 788-800.

[8] N. Rull, R. P. Ollier, G. Francucci, E. S. Rodriguez, and V. A. Alvarez, Effect of the addition of nanoclays on the water absorption and mechanical properties of glass fiber/up resin composites, Journal of Composite Materials, 0, (2014).
[9] N. Othman, Characterisation and Properties of Bentonit/Polyprophylene Composite, Universiti Sains Malaysia, (2007).

[10] N. Chitraningrum, Sifat Mekanik dan Termal Pada Bahan Nanokomposit Epoxy-Clay Tapanuli, Tugas Akhir, Universitas Indonesia, Depok, (2008).

[11] N. Bukit, E. Frida, and M. H. Harahap, Preparation Natural Bentonit in Nano Particle Material as Filler Nanocomposite High Density Poliethylene (Hdpe), Chemistry and Materials Research, 3, (2013) 10-20.

[12] S. Anandhan and S. Bandyopadhyay, Polymer Nanocomposites : From Synthesis to Applications, Nanocomposites and Polymers with Analytical Methods, (2011).

[13] S. F. Burlatsky, V. V. Atrazhev, D. V. Dmitriev, V. I. Sultanov, E. N. Timokhina, E. A. Ugolkova, S. Tulyani, and A. Vincitore, Surface Tension Model for Surfactant Solutions at The Critical Micelle Concentration, (2013).

[14] S. J. Ahmadi, H. Yodong, and W. Li, Synthesis of EPDM/Organoclay Nanocomposites : Effect of The Clay Exfoliation on Structure and Physical Properties, Iranian Polymer Journal, 13, (2004) 415-422.

[15] S. S. Ray, M. Okamoto, Polymer / Layered Silicate Nanocomposites : A Review From Preparation to Processing, Prog. Polym. Sci., 28, (2003) 1539-1641.

[16] T. P. Selvin, J. Kuruvilla, and T. Sabu, Mechanical Properties of Titanium DioxideFilled Polystyrene Microcomposites, Materials Letters 58, (2004) 281-289.

[17] W. J. Ward, G. L. G. Jr, M. M. Alger, and T. J. Stanley, Gas Barrier Improvement Using Vermiculite And Mica In Polymer Films, Journal of Membrane Science, 55, (1991) 173-180.

[18] X. Liu, Q. Wu, L. A. Berglund, J. Fan, and Z. Qi, Polyamide 6-Clay Nanocomposites /Polypropylene-Grafted-Maleic Anhydride Alloys, Polymer, 42, (2001) 8235-8239.

[19] Z. Masyithah, Optimasi Sintesis Surfaktan Alkanolamida Dari Asam Laurat Dengan Metode Dietanolamida dan N-Metil Glukamina Secara Enzimatik, Disertasi, Universitas Sumatera Utara, (2010). 